\title{
Morphological and Pathological Variability in Midrib and Stalk Isolates of Colletotrichum falcatum, the Cause of Red Rot of Sugarcane in North India
}

\author{
Rakesh kumar $^{1 *}$, Bipen Sharma², S. K. Sandhu² and S. K. Biswas ${ }^{1}$ \\ ${ }^{1}$ Dept. of Plant Pathology, CSA University of Agriculture \& Technology, Kanpur (208 002), India \\ ${ }^{2}$ Dept. of Plant Breeding and Genetics, Punjab Agricultural University, Ludhiana (141 004), India
}

\section{Article History}

Manuscript No. AR1368

Received in $31^{\text {st }}$ March, 2015

Received in revised form $15^{\text {th }}$ June, 2015

Accepted in final form $5^{\text {th }}$ August, 2015

\section{Correspondence to}

"E-mail: rakeshkumarpau@gmail.com

\section{Keywords}

Sugarcane, Colletotrichum falcatum, morphological characters, isolates, pathogenic variability

\begin{abstract}
Morphological, cultural and pathogenic variability of seven isolates of C. falcatum revealed that the average conidial size of midrib and stalk isolates varied from 23.0$27.5 \times 5.7-7.0 \mu \mathrm{m}$ and $26.8-35.0 \times 7.6-8.0 \mu \mathrm{m}$ respectively. Two midrib isolates namely MR-5 and MR-6 from CoJ 85 and one stalk isolate CF- 06 from CoJ 85 were relatively fast growing with an average colony diameter in the range of 13.3-13.6 mm, 36.5$36.9 \mathrm{~mm}$ and $84.1-84.2 \mathrm{~mm}$ and 13.5-13.9, 38.5 and 84.9 after 3,5 and 7 days of incubation, respectively. All the midrib isolates showed low and stalk isolates low, medium and high sporulation which ranged from 2.08 to $16.67 \times 105 / 9 \mathrm{~mm}$ disc (low), 16.67 to $29.17 \times 105 / 9 \mathrm{~mm}$ disc (medium) and 29.17 to $41.67 \times 105 / 9 \mathrm{~mm}$ disc (high). On the basis of morphological characters, midrib isolates produced dark type and stalk isolates produced with light and dark type colony colour. Pathogenic variability in midrib and stalk isolates of C. falcatum was studied on fourteen host differentials. On the basis of reaction expressed by seven midrib red rot isolates were grouped into five pathotypes based on their virulence. Group I designated as MR $\mathrm{Pb}-1$ from $\mathrm{CoJ}$ 85 (Isolate MR-5 and MR-6) was highly virulent and produced intermediate reaction on 6 differentials and stalk red rot isolates were grouped into four pathotypes based on their virulence. Group I designated as $\mathrm{CF} \mathrm{Pb}-1$ from $\mathrm{CoJ} 85$ (Isolate MR-5 and MR-6) was highly virulent and produced susceptible reaction on 10 differentials. A positive correlation between virulence and rate of growth was observed.
\end{abstract}

\section{Introduction}

Sugarcane (Saccharum officinarum) is one of the most important agro industrial crops of our country next to textile industry. Though it is largely a tropical crop, it is also grown in sub-tropical belt of the country, which is a major concern to the total pool of sugar production. Red rot caused by Colletotrichum falcatum Went is a devastating fungal disease of sugarcane. It reduces yield and causes deterioration in juice quality leading to economic losses for both growers and millers. It occurs in many cane growing countries but a continuous threat for subtropical countries. Most commercial varieties in India are susceptible to red rot to varying degree. Besides causing losses in yield and quality, it is also responsible for varietal failure in this crop. Variability and high adaptability of the pathogen endangers the very existence of the agronomically potential cultivars. It is the variability of the fungus due to which some sugarcane varieties are unstable in their resistance to the disease. Often a new variety resistant to prevailing isolates of red rot pathogen at the time of release may succumb to infection later on by the appearance of a new virulent isolate of the pathogen and this factor is responsible for the replacement of many commercial varieties like $\mathrm{CoJ} 64, \mathrm{CoJ}$ $82, \operatorname{CoJ} 84$ and Co 1148 in the state. The frequent breakdown of varietal resistance is due to variability in the casual fungus C. falcatum. The red rot pathogen exhibits greater variation in cultural characters, conidial morphology and germination and appresorial characters.

Expression of the disease may vary depending upon the nature of infection and prevailing environmental conditions and also among the isolates are significant constraint in assessing durable resistance to red rot is the occurrence of variability within the pathogen in the form of strains of the fungus. This results in frequent breakdown of resistance under field conditions. $C$. falcatum undergoes adaptive changes in relation to the host varieties cultivated, with subsequent alterations in the virulence pattern of the fungus. Further it has been found that isolates 
of $C$. falcatum are often unstable in their pathogenicity with a tendency to pass irreversibly into an avirulent phase. Therefore, the study was undertaken in the present investigation.

\section{Materials and Methods}

2.1. Survey, collection, isolation and maintenance of isolates

Diseased samples of midrib and stalk red rot of sugarcane were collected from different places of Punjab during 2011 and laboratory experiment was conducted at Department of Plant Breeding and Genetics, PAU Ludhiana during 2011. Monoconidial cultures were obtained through single spore isolation technique. A suspension of spores was prepared from 7-day old culture, dispersed on 2\% water agar Petri plates and incubated at $25 \pm 1{ }^{\circ} \mathrm{C}$. Single spore was marked under microscope with the help of fine tip of marker pen, picked with sterilized cork borer and transferred to Oat meal agar medium (Vishunavat and Kolte, 2005) slants for growth.

\subsection{Comparison of cultural characters}

The experiment was conducted at Department of Plant Pathology, PAU, Ludhiana, during 2011. The Oat meal agar Petri plates were inoculated in the centre with actively growing $5 \mathrm{~mm}$ mycelial disc having spores obtained from 7 days old culture and each isolate was replicated thrice using one Petri dish for each replicate. The morphological and cultural characteristics (colony diameter, colony colour, growth pattern, sporulation) were recorded after 7 days of incubation. Conidial size of each isolate was measured with the help of an ocular micrometer. Spore suspensions of different isolates were made from the cultures by dipping in distilled water. A drop of spore suspension on glass slide was observed under compound microscope and observations on conidial length and breadth were recorded. Fifty conidia were measured in each isolate separately and their averages were worked out.

\subsection{Multiplication of inoculum and method of inoculation}

Each midrib and stalk isolates of $C$. falcatum collected from different sugarcane varieties were multiplied on oat meal agar medium in Petri plates at $25 \pm 1{ }^{\circ} \mathrm{C}$. For inoculations, freshly sporulating 7-10 days old cultures were used. The spores were washed with sterile distilled water and homogenized by shaking and spore suspensions with concentration of $2 \times 10^{4}$ conidia $\mathrm{ml}^{-1}$ was maintained. Fourteen sugarcane differentials namely Baragua (S. officinarum), Khakai (S. sinense), SES 594 (S. spontaneum), $\mathrm{CoS}$ 767, Co 975, BO 91, CoC 671, Co 7717, Co 997, CoJ 64, Co 1148, Co 419, Co 62399 and Co 8436 were planted in $1^{\text {st }}$ week of march in the field area using two budded setts as per recommended practices. Twenty canes of each differential, viz., Baragua (S. officinarum), Khakai ( $S$. sinense), SES 594 (S. spontaneum), CoS 767, Co 975, BO
91, CoC 671, Co 7717, Co 997, CoJ 64, Co 1148, Co 419, Co 62399 and CoS 8436 were inoculated by plug method (Srinivasan and Bhatt, 1961) with seven midrib and stalk isolates namely MR-1, MR-2, MR-3, MR-4, MR-5, MR-6 and MR-7 and CF-01, CF-02, CF-03, CF-04, CF-05, CF-06 and $\mathrm{CF}-07$ respectively. The inoculations were done in the third internode from the base of the standing canes injecting

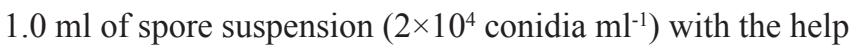
of hypodermic syringe. The core was then replaced and the opening finally sealed with modeling clay.

\subsection{Disease scoring}

Disease data were recorded after 60 days of inoculation. The condition of the top was recorded and the canes splitted longitudinally. Observations were recorded on the number of internodes transgressed by the pathogen, lesion width and white spots. The canes were rated 0-9 as per scale of Srinivasan and Bhatt, 1961.

\section{Results and Discussion}

\subsection{Isolation of the pathogen}

Isolations were made from the infected midrib and stalks samples showing typical red rot symptoms collected from different areas of Punjab including Dasuaya, Butter Sevian and Gurdaspur. Single spore isolations were made from the cultures.

In all seven midrib and stalk isolates viz., MR-1, MR-2, MR-3, MR-4, MR-5, MR-6 and MR-7 and CF-01, CF-02, CF-03, CF04, CF-05, CF-06 and CF-07 respectively of Colletotrichum falcatum were obtained. Whitish grey to grayish white fungus was isolated from both midrib and stalks sample on the basis of morphological characters given in various reports (Sarkar, 1960, Prakasan and Venkatareddy, 1961; Sharma, 1970)

\subsection{Morphological/Pathological characters of different} isolates

\subsubsection{Morphological characters}

\subsubsection{Colony diameter of midrib and stalk isolates}

All the midrib and stalk isolates namely MR-1, MR-2, MR-3, MR-4, MR-5, MR-6 and MR-7 and CF-01, CF-02, CF-03, CF-04, CF-05, CF-06 and CF-07 respectively were cultured on oat meal agar medium in Petri dishes and colony diameter was measured after 3,5 and 7 days of incubation at $25 \pm 1{ }^{\circ} \mathrm{C}$ and data is given in (Table 1).

\subsection{Midrib isolates}

After 3 days of incubation three isolates, viz., MR-5, MR-6 and MR-7 were relatively fast growing with an average colony diameter in the range of 13.3-13.6 mm. These three isolates were statistically at par with each other so these constituted 


\begin{tabular}{|c|c|c|c|c|c|c|c|c|c|}
\hline \multirow[t]{2}{*}{ Midrib isolates } & \multicolumn{3}{|c|}{ Colony Diameter (mm) } & \multirow{2}{*}{$\begin{array}{c}\text { (A) } \\
\text { "Overall mean }\end{array}$} & \multirow[t]{2}{*}{ Stalk isolates } & \multicolumn{3}{|c|}{ Colony Diameter (mm) } & \multirow{2}{*}{$\begin{array}{c}\text { (B) } \\
\text { *Overall mean }\end{array}$} \\
\hline & 3 days & 5 days & 7 days & & & 3 days & 5 days & 7 days & \\
\hline MR-1 & 12.8 & 35.7 & 80.7 & 43.5 & CF- 01 & 12.8 & 36.8 & 82.0 & 43.5 \\
\hline MR-2 & 12.7 & 35.4 & 80.9 & 42.6 & $\mathrm{CF}-02$ & 12.4 & 35.3 & 81.6 & 42.6 \\
\hline MR-3 & 12.9 & 36.6 & 81.6 & 43.7 & CF-03 & 12.7 & 37.2 & 82.5 & 44.1 \\
\hline MR-4 & 12.3 & 35.2 & 78.7 & 42.1 & CF-04 & 13.4 & 37.4 & 84.2 & 45.0 \\
\hline MR-5 & 13.6 & 36.9 & 84.2 & 44.9 & CF-05 & 12.9 & 35.9 & 82.4 & 43.7 \\
\hline MR-6 & 13.3 & 36.7 & 84.1 & 44.7 & CF-06 & 13.9 & 38.5 & 84.9 & 45.8 \\
\hline MR-7 & 13.5 & 36.5 & 80.6 & 43.5 & CF-07 & 13.5 & 36.6 & 82.7 & 43.8 \\
\hline Mean & 13.0 & 36.1 & 81.6 & 43.5 & Mean & 13.1 & 36.7 & 82.3 & 44.1 \\
\hline $\mathrm{CD}(p=0.05)$ & 0.31 & 0.39 & 0.52 & NS & $\mathrm{CD}(p=0.05)$ & 0.42 & 0.53 & 0.61 & NS \\
\hline
\end{tabular}

${ }^{*}$ Factor $\mathrm{A}($ Overall mean of midrib isolates $)=\mathrm{NS}$; ${ }^{*}$ Factor $\mathrm{B}($ Overall mean of midrib isolates $)=\mathrm{NS} ; \mathrm{A} \times \mathrm{B}=\mathrm{NS}$

Group I. Three isolates MR-1, MR-2 and MR-3 statistically at par showed an average colony diameter in the range of 12.7 $-12.9 \mathrm{~mm}$ and formed group II. The last group III included one isolates namely MR-4 with an average colony diameter 12.3 $\mathrm{mm}$. and was relatively. Their existed significant difference among all the 3 groups.

Four isolates, namely MR-3, MR-5, MR-6 and MR-7 were relatively fast growing after 5 days of incubation with an average colony diameter of 36.5-36.9 $\mathrm{mm}$. These were statistically at par with each other and constituted group I. Group II comprised of two isolates namely MR-1 and MR-2 with an average colony diameter $35.7 \mathrm{~mm}$. The last group III consisted of one isolates MR-4 with an average colony diameter $35.2 \mathrm{~mm}$.

After 7 days of incubation two isolates namely MR-5 and MR-6 were relatively fast growing with an average colony diameter in the range of 84.1-84.2 $\mathrm{mm}$. These were statistically at par with each other and constituted group I. Group II comprised one isolates, MR-3 with an average colony diameter 81.6. Three isolates, namely MR-1, MR-2 and MR-7 statistically at par showed an average colony diameter in the range of 80.6-80.9 $\mathrm{mm}$ and constituted group III. The last Group IV comprised one isolate MR-4 with an average colony diameter in the 78.7 $\mathrm{mm}$. This last IV group having one isolate were relatively slow growing after 7 days of incubation.

By considering the observations upto 7 days of incubation it was found that isolates namely MR-5 and MR-6 from CoJ 85 showed consistent were relatively fast growing with an average colony diameter in the range of 13.3-13.6 mm, 36.5$36.9 \mathrm{~mm}$ and 84.1-84.2 mm while isolate MR-4 from CoJ 83 showed slow growing with an average colony diameter in the range of 12.3, 35.2 and $78.7 \mathrm{~mm}$ on 3, 5, 7 days respectively, compared to all other isolates. All the rest test isolates showed medium growth.

\subsection{Stalk isolates}

After 3 days of incubation two isolates, viz., CF-06 and CF-07 were relatively fast growing with an average colony diameter in the range of 13.5-13.9 mm. These two isolates were statistically at par with each other so these constituted Group I. Group II comprised of one isolates, $\mathrm{CF}-4$ with an average colony diameter $13.4 \mathrm{~mm}$. Three isolates CF-01, CF-03, and CF-05 statistically at par showed an average colony diameter in the range of 12.7-12.9 mm and formed group III. The last group IV included one isolates namely CF-02 with an average colony diameter $12.4 \mathrm{~mm}$.

One isolate CF-06 was relatively fast growing after 5 days of incubation with an average colony diameter of $38.5 \mathrm{~mm}$ and constituted group I. Two isolates CF-03 and CF-04 statistically at par showed an average colony diameter in the range of 37.2-37.4 mm and formed group II. Group III also comprised of two isolates CF-01 and CF-07 which showed an average colony diameter of 36.6-36.8 mm. The Group IV and Group V each comprised one isolate, $\mathrm{CF}-05$ and CF-02 with an average colony diameter $35.9 \mathrm{~mm}$ and $35.3 \mathrm{~mm}$ respectively.

After 7 days of incubation one isolate namely CF-06 was relatively fast growing with an average colony diameter 84.9 $\mathrm{mm}$ and constituted group I. one isolate, CF-04 showed an average colony diameter $84.2 \mathrm{~mm}$ and constituted group II. Group III comprised of three isolates, namely CF-03, CF05 and CF-07 statistically at par showed an average colony diameter in the range of $82.4-82.7 \mathrm{~mm}$. Group IV comprised two isolates, namely CF-01 CF-02 statistically at par showed an average colony diameter in the range of $81.6-82.0 \mathrm{~mm}$. The isolates of this group IV were relatively slow growing after 7 days of incubation.

By considering the observations upto 7 days of incubation it was found that isolate namely CF-06 from CoJ 85 showed 
consistent fast growth $(13.9,38.5$ and $84.9 \mathrm{~mm}$ on 3, 5 and 7 days respectively) compared to all other isolates while isolate CF-02 from CoJ 64 showed slow growth upto 12.4, 35.3 and $81.6 \mathrm{~mm}$ on 3,5 and 7 days respectively) compared to all other isolates. All the remaining tested isolates showed medium growth.

Grouping of various midrib and stalk isolates of Colletotrichum falcatum on the basis of colony diameter $(\mathrm{mm})$ show in Table 2. On the basis of overall mean of colony diameter after 3,5 and 7 days incubation of both all midrib and stalk isolates were statistically non significant that mean no differences between colony diameters in between midrib and stalk isolates.

Statistically all the stalk isolates were significant to each other after 3, 5 and 7 days incubation in respect to colony diameter. Closely similar results were also reported by Srinivasan et al. (1969) for midrib isolates and similar results were also reported by Viswanathan et al. (2003) for stalk isolates. They reported great variation in the mycelial growth among the strains while working on nine major C. falcatum pathotypes namely Cf-671, Cf-90063, Cf-9201, Cf-419, Cf-997, Cf-1148, Cf-7717, Cf-64 and Cf-767.

\subsubsection{Colony Characters of midrib and stalk isolates}

Observations pertaining to colony colour, pattern of growth and sporulation of different isolates on oat meal agar medium after 7 days of incubation are summarized in Table 3 and Figure 1.

\subsection{Midrib isolates}

\subsection{Colony colour}

Four midrib isolates (MR-3, MR-4, MR-6 and MR-7) were having grayish white and one isolate MR-2 was having whitish gray colonies. Two isolates MR-1 and MR-5 were having grey type colonies. All the isolates were considered as dark type.

\subsection{Mycelium pattern}

Out of 7 isolates, 3 isolates namely MR-1, MR-2 and MR-3 showed fluffy pattern of mycelial growth where as isolates MR-4, MR-5, MR-6 and MR-7 were having less fluffy pattern of mycelial growth.

\subsection{Sporulation}

All the midrib isolates showed low type sporulatisons.

\subsection{Stalk isolates}

\subsection{Colony colour}

Out of 7 stalk isolates, three isolates namely CF-01, CF-02 and $\mathrm{CF}-04$ were having whitish grey colonies and two isolates CF-05 and CF-06 showed grayish white colonies. They were considered a light type isolates. Similarly, isolates CF-03 and CF-07 having grayish white colonies but considered as a dark type isolates.

\subsection{Mycelium pattern}

Isolates CF-01, CF-02 and CF 04 showed more fluffy pattern of mycelial growth whereas isolates namely CF-03, CF-05, CF-06 and CF-07 showed fluffy type of mycelial growth.

\subsection{Sporulation}

Out of 7 isolates, 3 isolates namely CF-03, CF-04 and CF- 07 showed low sporulation. Two isolates namely CF- 01 and CF02 showed medium sporulation and CF-05 and CF-06 showed high sporulation.

The results of present study clearly showed that differences between midrib and stalk isolates in respects to colony colour, mycelial pattern and sporulation. Midrib isolates produced only dark type of colony, less fluffy to fluffy with mycelial growth with less sporulatin whereas in stalk isolates produced light and dark type of colony, fluffy to more fluffy mycelial growth with low, medium and high spoulation.

Similar results were reported by Lewin et al. (1978); Shukla et al. (2001) in respect to colony characteristics of midrib stalk isolates. They observed that isolations from diseased stalks yielded both light and dark type isolates where as the isolates

Table 2: Groups of various midrib and stalk isolates of Colletotrichumfalcatumon the basis of Colony diameter (mm)

\begin{tabular}{|c|c|c|c|c|c|c|}
\hline \multirow{2}{*}{$\begin{array}{l}\text { Group } \\
\text { no. }\end{array}$} & \multicolumn{3}{|c|}{ Midrib } & \multicolumn{3}{|c|}{ Stalk } \\
\hline & 3 days & 5 days & 7 days & 3 days & 5 days & 7 days \\
\hline Group I & $\begin{array}{l}\text { MR-5, MR-6 } \\
\text { and MR-7 }\end{array}$ & $\begin{array}{c}\text { MR-3, MR-5, } \\
\text { MR-6 and MR-7 }\end{array}$ & MR-5 and MR-6 & $\begin{array}{l}\text { CF-06 and } \\
\text { CF-07 }\end{array}$ & CF-06 & CF-06 \\
\hline Group II & $\begin{array}{c}\text { MR-1, MR-2 } \\
\text { and MR-3 }\end{array}$ & MR-1 and MR-2 & MR-3 & CF-04 & $\mathrm{CF}-03$ and $\mathrm{CF}-04$ & CF-04 \\
\hline Group III & MR-4 & MR-4 & $\begin{array}{c}\text { MR-1, MR-2 and } \\
\text { MR-7 }\end{array}$ & $\begin{array}{c}\text { CF-01, CF-03 } \\
\text { and CF-05 }\end{array}$ & CF-01 and CF-07 & $\begin{array}{c}\mathrm{CF}-03, \mathrm{CF}-05 \text { and } \\
\text { CF-07 }\end{array}$ \\
\hline Group IV & & & MR-4 & CF-02 & CF-05 & CF-01 and CF-02 \\
\hline Group V & & & & & CF-02 & \\
\hline
\end{tabular}




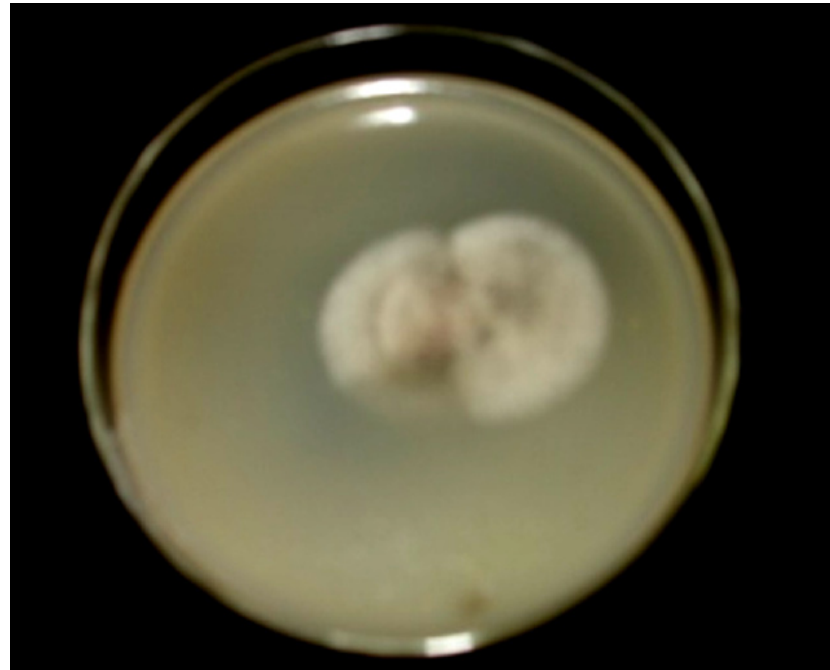

Dark type colony after 3 days (Midrib isolate)

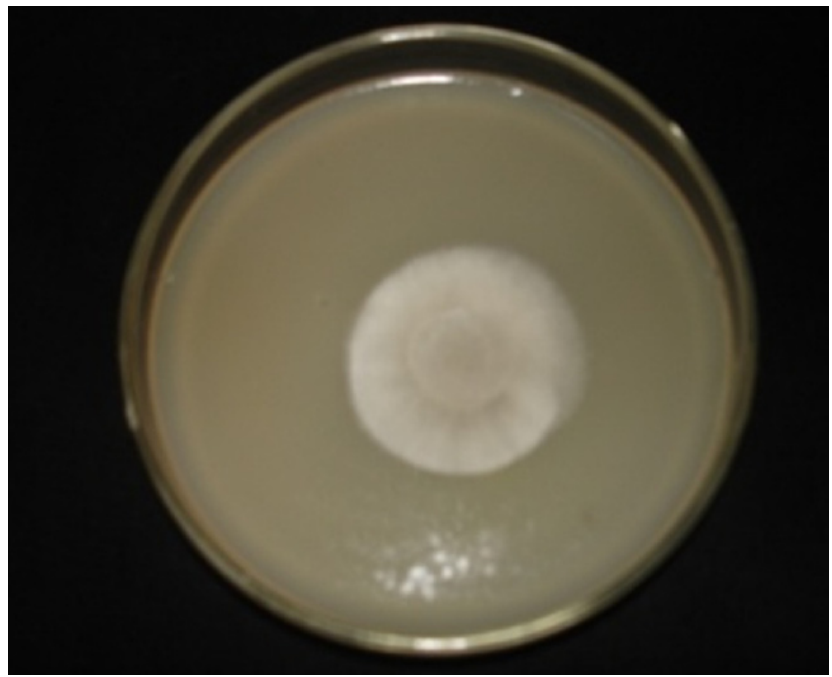

Light type colony after 3 days (Midrib isolate)

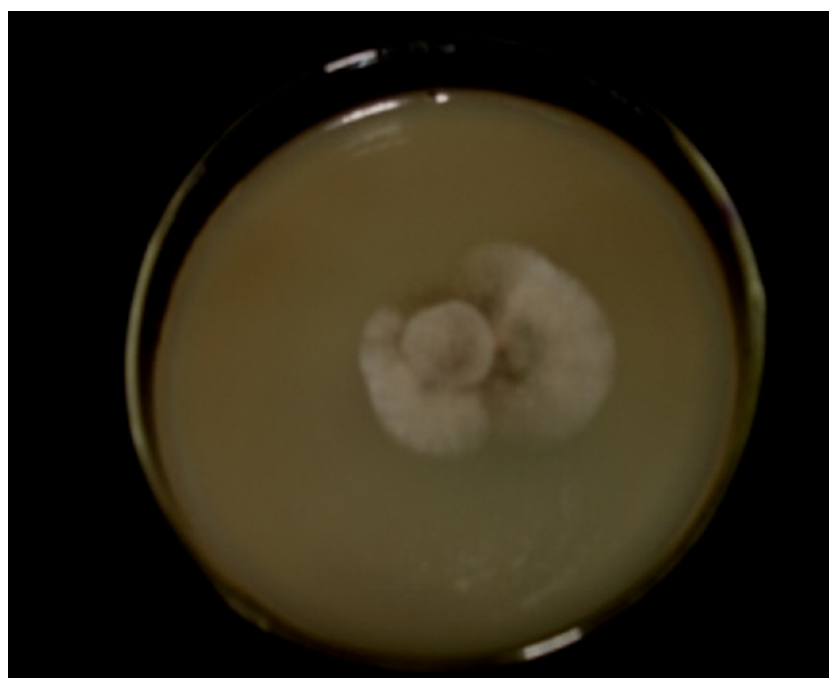

Dark type colony after 3 days (Stalk isolate)

$\infty$

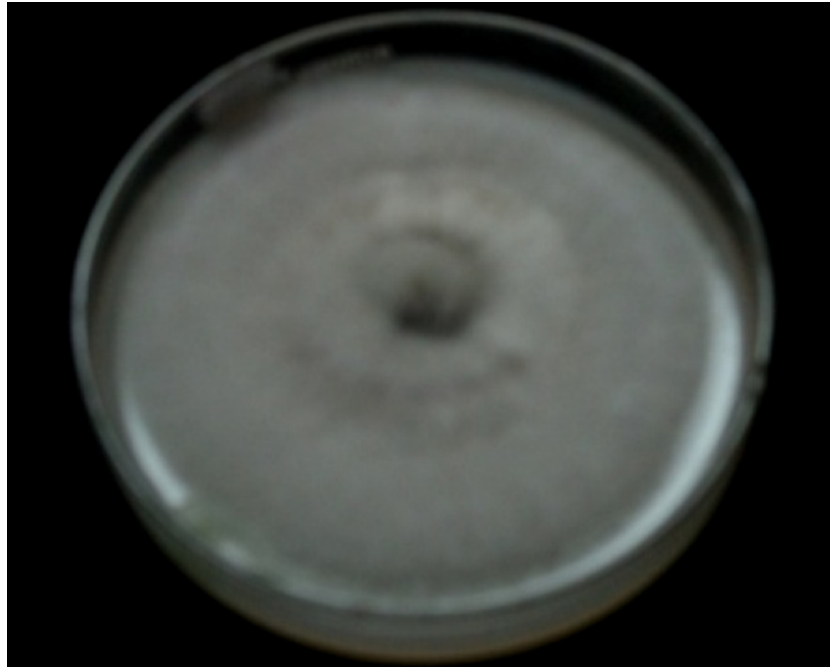

Dark type colony after 7 days (Midrib isolate)

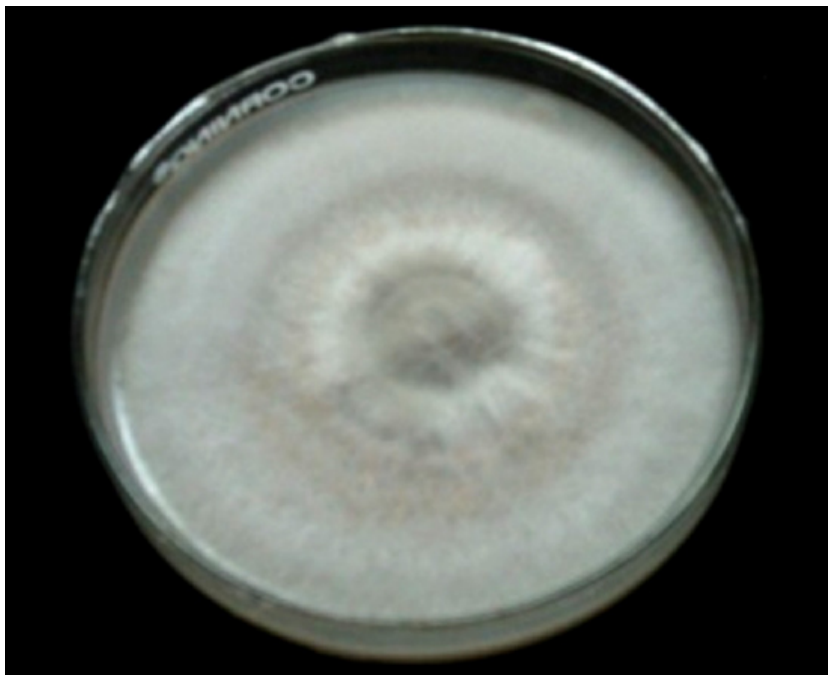

Dark type colony after 7 days (Midrib isolate)

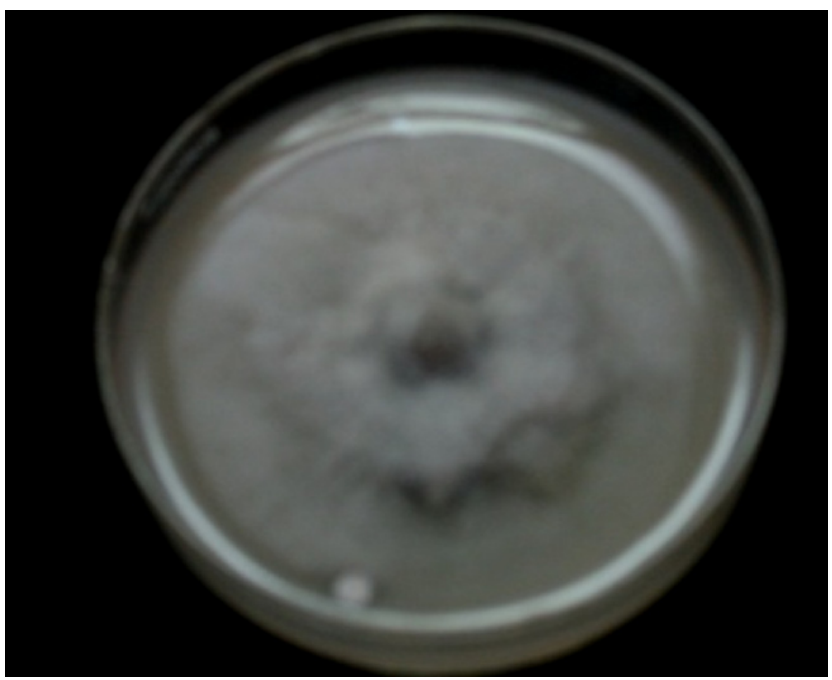

Dark type colony after 7 days (Stalk isolate)

Continue... 


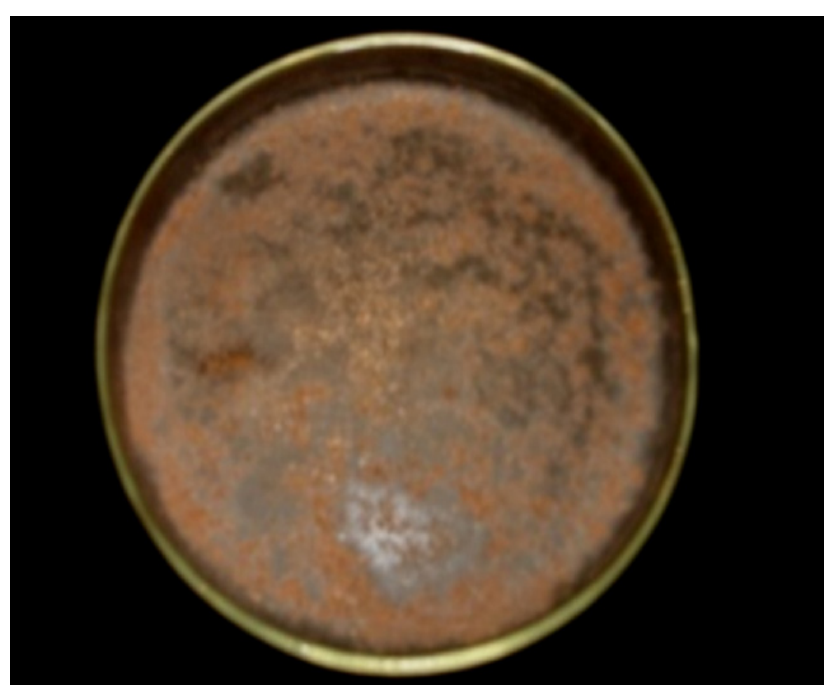

Sporulation of fungus C. falcatum $(40 \times)$ (Stalk isolate)

Figure 1: Mycelium Character of midrib and stalk isolate (MR-5 and CF-05 respectively) of Colletotrichum falcatum Went

obtained from midrib lesions were of dark type only. Abbott $(1935,1938)$ observed that the stalk isolates have two distinct dark and light type races were recognized on the basis of colour and texture and found that dark type sporulate sparingly and light type sporulate abundantly. Similar results were reported by various workers in India regarding existence of variability in C. falcatum based on cultural and morphological characters and relative pathogenic behaviour on sugarcane varieties (Sarkar 1960; Prakasam and Venkatareddy 1961; Sharma 1970; Waraitch 1986). Jothi (1989) divided 30 isolates of $C$. falcatum into 5 groups on the basis of colour, texture and sporulation.

\subsubsection{Conidial size $(\mu \mathrm{m})$ of midrib and stalk isolates}

Conidial dimensions of different isolates from infected midrib and stalks were measured in water drops with the help of ocular micrometer, average measurement of length and breadth of different isolates are given in Table 4 and conidia of midrib and stalk isolates shows in Figure 2.

\subsection{Midrib isolates}

The average size of different midrib isolates varied from $25.7 \times 6.4 \mu \mathrm{m}$. Among these isolates MR-1 from $\mathrm{CoJ} 64$ showed maximum size of $27.0 \times 7.0 \mu \mathrm{m}$ followed by isolate MR-2, MR-3, MR-5, MR-6 and MR-7. Isolate MR-4 from CoJ 83 showed least size of $23.0 \times 5.7 \mu \mathrm{m}$ as compared to other isolates.

\subsection{Stalk isolates}

The mean size of different stalk isolates varied from $29.9 \times 7.6$ $\mu \mathrm{m}$. Among these isolates CF-01 from CoJ 64 showed maximum size of $35.0 \times 8.7 \mu \mathrm{m}$ followed by isolate $\mathrm{CF}-02$, CF-03, CF-04, CF-06 and CF-07. Isolate CF-06 from CoJ
85 showed least size of $26.5 \times 7.0 \mu \mathrm{m}$ as compared to other isolates.

Observation in Table 4 clearly showed that the size of conidia of midrib isolates were less than stalk isolates. Similar results were reported by Lewin et al. (1978) they observed the size of conidia from midrib lesion were 7.7-29.0 $\mu \mathrm{m}$ (average 22.4) $\times$ 5.8-9.7 $\mu \mathrm{m}$ (average 7.4). Abbott (1938) reported that length of conidia from stalk isolates ranged from 16-40 $\mu \mathrm{m}$ while Went (1893) reported it $25 \mu \mathrm{m}$. Chona and Srivastava (1960) reported the length of conidia of 32 isolates being a minimum of 10 $\mu \mathrm{m}$ and maximum of $36 \mu \mathrm{m}$. Various reports are available on the variation of conidia morphology and dimensions, conidial size of 17.1 to $25.8 \times 4.5$ to $6.8 \mu \mathrm{m}$ (Pandey and Sakel, 1974), varying length of 23 to $30 \mu \mathrm{m}$ (Khirbat et al., 1980), sickle shaped conidia measuring $16-40 \times 5.7 \mu \mathrm{m}$ in size with an oil globule in the middle (Agnihotri, 1983) and 15-42.6×3.7-8.6 $\mu \mathrm{m}$ (Jothi, 1989).

\subsubsection{Pathological characters}

Pathogenic variability in midrib and stalk red rot caused by Colletotrichum falcatum was studied on fourteen host differentials viz., Baragua (S. officinarum), Khakai (S. sinense), SES 594 (S. spontaneum), CoS 767, Co 975, BO 91, CoC 671, Co 7717, Co 997, CoJ 64, Co 1148, Co 419, Co 62399 and CoS 8436. These differentials were inoculated by plug method on 10-08-2009 using conidial suspension separately with each of seven red rot isolates collected from the Punjab State. These midrib isolates namely MR-1 and MR-2 from CoJ 64, MR-3 from CoJ 82, MR-4 from CoJ 83, MR-5 and MR-6 from CoJ 85, MR-7 from CoJ 88 and stalk isolates were CF-01 and CF-02 from CoJ 64, CF- 03 from CoJ 82, CF-04 from CoJ 83, CF-05 and CF-06 from CoJ 85 and CF-07 from CoJ 88.

Observations on disease reactions were recorded by split opening the canes 60 days after inoculation and various criteria

Table 4: Conidial size $(\mu \mathrm{m})$ of midrib and stalk isolates of Colletotrichum falcatum

\begin{tabular}{|c|c|c|c|}
\hline \multirow{2}{*}{$\begin{array}{l}\text { Midrib } \\
\text { isolates }\end{array}$} & Size $(\mu \mathrm{m})$ & \multirow{2}{*}{$\begin{array}{l}\text { Stalk } \\
\text { isolates }\end{array}$} & \multirow{2}{*}{$\frac{\text { Size }(\mu \mathrm{m})}{\text { Length } \times \text { breadth }}$} \\
\hline & Length $\times$ breadth & & \\
\hline MR-1 & $27.0 \times 7.0$ & CF-01 & $35.0 \times 8.7$ \\
\hline MR-2 & $26.5 \times 6.9$ & CF-02 & $34.8 \times 8.5$ \\
\hline MR-3 & $25.1 \times 6.3$ & CF-03 & $28.5 \times 7.5$ \\
\hline MR-4 & $23.0 \times 5.7$ & CF-04 & $27.5 \times 7.5$ \\
\hline MR-5 & $26.4 \times 6.0$ & CF-05 & $27.0 \times 7.3$ \\
\hline MR-6 & $26.5 \times 5.9$ & CF-06 & $26.8 \times 7.0$ \\
\hline MR-7 & $25.5 \times 6.7$ & CF-07 & $29.5 \times 7.8$ \\
\hline Mean & $25.7 \times 6.4$ & Mean & $29.9 \times 7.6$ \\
\hline
\end{tabular}

Average of 50 observations 


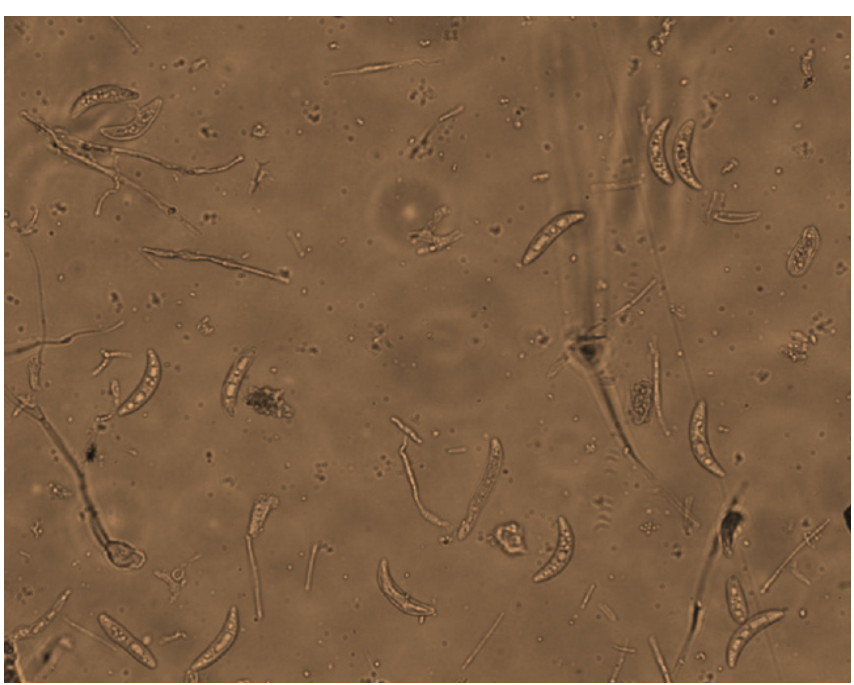

Midrib isolate

Figure 2: Conidia of midrib and stalk isolate (MR-5 and CF-05 respectively) of Colletotrichum falcatum Went. at 40x

viz., nature of white spots, nodal transgression, lesion width and condition of tops were taken into consideration for recording disease reactions (Anonymous 1999). Host disease reactions were finally categorized into three groups viz., resistant $(\mathrm{R})$, susceptible (S) and intermediate (I) for distinct differentiation of pathotypes. Information generated on the behavior of various midribs and stalk isolates on the differentials during the year 2009-10.

\subsubsection{Midrib isolates}

Data presented in Table 5 clearly demonstrated that none of the midrib isolates exhibited susceptible $(\mathrm{S})$ reaction on any of 14 differentials whereas all these midrib isolates MR-1 to MR-7, expressed resistant reaction on Baragua, SES 594, CoS 767, Bo 91, Co 7717, Co 1148, Co 419, CoS 8436.

Differential Khakai and CoC 671 showed intermediate reaction by the isolates namely MR-1, MR-2, MR-4, MR-5, MR-6 and MR-7 but isolate MR-3 was expressed resistant reaction on both differentials. Similarly, differentials Co 62399 and Co 975 expressed resistant reaction by 5 isolates namely MR-1, MR-2, MR-3, MR-4 and MR-7 and isolates MR-5 and MR-6 showed intermediate reaction on both differentials. Isolates MR-1, MR-2, MR-5 and MR-6 produced intermediate reaction on differential Co997 and CoJ 64 and isolate MR-4 produced resistant reaction on both differentials but isolates MR-3 and MR-7 both produced resistant reaction on differential Co997 and intermediate reaction on CoJ 64.

Statistically all the treatments (Midrib isolates) were non significant on differentials Baragua, Khakai, SES 594, CoS 767, Bo 91, CoC 671, CoJ 64, Co 7717, Co 1148, Co 419 and $\mathrm{CoS} 8436$ with respects to pathogenic reactions but these treatments were significant on differentials Co 997, Co 62399

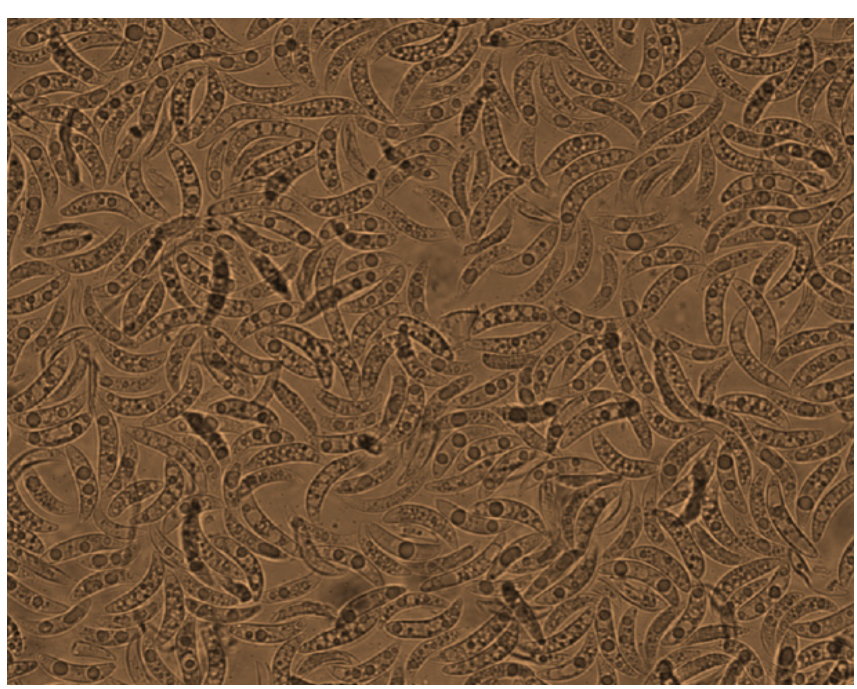

Stalk isolate

and Co 975.

On the basis of reaction expressed by 7 midrib red rot isolates on 14 differentials, they can be grouped into 5 pathotypes based on their virulence (Table 6). Isolates MR-5, MR-6 from COJ 85 both produced intermediate reaction on 6 and resistant reaction on 8, Isolates MR-1 and MR-2 from CoJ 64 showed intermediate reaction on 4 and resistant reaction on 10, Isolates MR-7 from CoJ 88 showed intermediate reaction on 3 and resistant reaction on 11, Isolates MR-4 from CoJ 83 showed intermediate reaction on 2 and resistant reaction on 12 and Isolates MR-3 from CoJ 82 showed intermediate reaction on 1 and resistant reaction on 13 .

The five pathotypes were designated as MR $\mathrm{Pb}-1$ from $\mathrm{COJ}$ 85 (Isolates MR-5 and MR-6); MR Pb-2 from CoJ 64 (Isolates MR-1 and MR-2); MR Pb-3 from CoJ 88 (Isolate MR-7); MR $\mathrm{Pb}-4$ from $\mathrm{CoJ} 83$ (MR-4) and MR Pb-5 from CoJ-82 (Isolate MR-3). MR Pb-1 was virulent pathotype among midrib isolates and produced intermediate reaction on 6 differentials out of 14 followed by MR Pb-2 pathotype. MR Pb-5 was found the least virulent pathotype which produced intermediate reaction only one differential.

\subsubsection{Stalk isolates}

Table 7 demonstrated that none of the stalk isolates exhibited resistant $(\mathrm{R})$ reaction on all of 14 differentials. All the isolates expressed susceptible reaction on Khakai, CoC 671, Co 997 and Co 62399 and resistant reactions expressed on Baragua, SES 594, Bo 91 and CoS 8436. Differentials CoJ 64 also showed susceptible reaction to all the tested isolates except intermediate reaction to $\mathrm{CF}-04$. Differentials $\mathrm{CoS} 767$ expressed three type reactions by all tested isolates. CF-01, CF-02 and CF03 produced resistant reactions, $\mathrm{CF}-05$ and $\mathrm{CF}-06$ produced 


\begin{tabular}{|c|c|c|c|c|c|c|c|c|c|c|c|c|c|c|c|c|}
\hline \multirow{2}{*}{$\begin{array}{l}\text { Sr. } \\
\text { no. }\end{array}$} & \multirow{2}{*}{$\begin{array}{l}\text { Iso- } \\
\text { lates }\end{array}$} & \multirow[t]{2}{*}{ Source } & \multicolumn{14}{|c|}{ Reaction } \\
\hline & & & $\begin{array}{l}\text { Bara- } \\
\text { gua }\end{array}$ & $\begin{array}{l}\text { Kha- } \\
\text { kai }\end{array}$ & $\begin{array}{l}\text { SES } \\
594\end{array}$ & $\begin{array}{l}\text { CoS } \\
767\end{array}$ & $\begin{array}{l}\text { BO } \\
91\end{array}$ & $\begin{array}{l}\mathrm{CoC} \\
671\end{array}$ & $\begin{array}{l}\text { Co } \\
7717\end{array}$ & $\begin{array}{l}\text { Co } \\
997\end{array}$ & $\begin{array}{l}\mathrm{CoJ} \\
64\end{array}$ & $\begin{array}{l}\text { Co } \\
1148\end{array}$ & $\begin{array}{l}\text { Co } \\
419\end{array}$ & $\begin{array}{l}\text { Co } \\
62399\end{array}$ & $\begin{array}{l}\text { Co } \\
975\end{array}$ & $\begin{array}{l}\text { CoS } \\
8436\end{array}$ \\
\hline 1. & MR-1 & CoJ 64 & $2.1 \mathrm{R}$ & $4.5 \mathrm{I}$ & $2.3 \mathrm{R}$ & $2.6 \mathrm{R}$ & $2.4 \mathrm{R}$ & $4.6 \mathrm{I}$ & $3.2 \mathrm{R}$ & $4.5 \mathrm{I}$ & $5.4 \mathrm{I}$ & $3.3 \mathrm{R}$ & $2.3 \mathrm{R}$ & $3.4 \mathrm{R}$ & $2.0 \mathrm{R}$ & $2.3 \mathrm{R}$ \\
\hline 2. & MR-2 & $\mathrm{CoJ} 64$ & $2.5 \mathrm{R}$ & $4.7 \mathrm{I}$ & $2.4 \mathrm{R}$ & $3.3 \mathrm{R}$ & $2.3 \mathrm{R}$ & $4.3 \mathrm{I}$ & $3.2 \mathrm{R}$ & $4.8 \mathrm{I}$ & $5.6 \mathrm{I}$ & $3.2 \mathrm{R}$ & $2.6 \mathrm{R}$ & $3.8 \mathrm{R}$ & $3.1 \mathrm{R}$ & $2.5 \mathrm{R}$ \\
\hline 3. & MR-3 & $\mathrm{CoJ} 82$ & $2.0 \mathrm{R}$ & $3.7 \mathrm{R}$ & $3.0 \mathrm{R}$ & $2.6 \mathrm{R}$ & $2.0 \mathrm{R}$ & $3.4 \mathrm{R}$ & $3.5 \mathrm{R}$ & $3.4 \mathrm{R}$ & $4.5 \mathrm{I}$ & $3.3 \mathrm{R}$ & $3.1 \mathrm{R}$ & $3.6 \mathrm{R}$ & $2.0 \mathrm{R}$ & $2.0 \mathrm{R}$ \\
\hline 4. & MR-4 & $\mathrm{CoJ} 83$ & $2.3 \mathrm{R}$ & $4.2 \mathrm{I}$ & $2.0 \mathrm{R}$ & $2.0 \mathrm{R}$ & $2.5 \mathrm{R}$ & $4.1 \mathrm{I}$ & $2.0 \mathrm{R}$ & $3.8 \mathrm{R}$ & $3.2 \mathrm{R}$ & $2.5 \mathrm{R}$ & $2.0 \mathrm{R}$ & $3.0 \mathrm{R}$ & $3.4 \mathrm{R}$ & $3.0 \mathrm{R}$ \\
\hline 5. & MR-5 & $\mathrm{CoJ} 85$ & $2.2 \mathrm{R}$ & $4.0 \mathrm{I}$ & $2.0 \mathrm{R}$ & $3.5 \mathrm{R}$ & $2.3 \mathrm{R}$ & 4.7 I & $3.6 \mathrm{R}$ & $4.3 \mathrm{I}$ & $4.6 \mathrm{I}$ & $3.3 \mathrm{R}$ & $3.6 \mathrm{R}$ & $4.5 \mathrm{I}$ & $4.3 \mathrm{I}$ & $2.0 \mathrm{R}$ \\
\hline 6. & MR-6 & $\mathrm{CoJ} 85$ & $2.2 \mathrm{R}$ & $4.8 \mathrm{I}$ & $2.0 \mathrm{R}$ & $3.8 \mathrm{R}$ & $2.5 \mathrm{R}$ & $4.5 \mathrm{I}$ & $3.8 \mathrm{R}$ & $4.7 \mathrm{I}$ & $5.3 \mathrm{I}$ & $3.5 \mathrm{R}$ & $3.3 \mathrm{R}$ & $4.4 \mathrm{I}$ & $4.1 \mathrm{I}$ & $2.0 \mathrm{R}$ \\
\hline 7. & MR-7 & $\mathrm{CoJ} 88$ & $2.6 \mathrm{R}$ & $4.8 \mathrm{I}$ & $2.8 \mathrm{R}$ & $2.0 \mathrm{R}$ & $2.2 \mathrm{R}$ & $4.2 \mathrm{I}$ & $3.0 \mathrm{R}$ & $3.5 \mathrm{R}$ & $4.4 \mathrm{I}$ & $3.2 \mathrm{R}$ & $2.0 \mathrm{R}$ & $3.3 \mathrm{R}$ & $2.7 \mathrm{R}$ & $2.2 \mathrm{R}$ \\
\hline \multicolumn{3}{|c|}{$\mathrm{CD}(p=0.05)$} & NS & NS & NS & NS & NS & NS & NS & 0.15 & NS & NS & NS & 0.32 & 0.25 & NS \\
\hline
\end{tabular}

Score-Rating; 0-4.0: Resistant (R); 4.1-6.0: Intermediate (I); >6.1: Susceptible (S)

Table 6: Pathogenic groups of various midrib isolates of Colletotrichum falcatum formed on the basis of virulence

\begin{tabular}{lcllll}
\hline Group no. & Isolates & \multicolumn{2}{c}{ Reaction } & $\begin{array}{l}\text { Pathogenic } \\
\text { group }\end{array}$ \\
\cline { 3 - 6 } & & \multicolumn{2}{c}{ I } & S & \\
\hline Group I & MR-5 and MR-6 & 8 & 6 & - & MR Pb-1 \\
Group II & MR-1 and MR-2 & 10 & 4 & - & MR Pb-2 \\
Group III & MR-7 & 11 & 3 & - & MR Pb-3 \\
Group IV & MR-4 & 12 & 2 & - & MR Pb-4 \\
Group V & MR-3 & 13 & 1 & - & MR Pb-5 \\
\hline
\end{tabular}

susceptible reactions whereas CF 04 and CF 07 produced intermediate reaction. Similarly, Differential Co 975 expressed resistant reactions by $\mathrm{CF}-03$ and $\mathrm{CF}-07$, susceptible reactions by $\mathrm{CF}-05$ and $\mathrm{CF}-06$ and intermediate reactions by $\mathrm{CF}-01$, $\mathrm{CF}-02$ and $\mathrm{CF}-04$ isolates.

Differential Co 7717, Co 1148 expressed two type reactions by all tested isolates. Isolates $\mathrm{CF}-01, \mathrm{CF}-02$ and $\mathrm{CF}-07$ produced intermediate reactions and CF-03, CF-04, CF-05 and CF-06 susceptible reaction on both differentials. Differential Co 419 gave three type of reaction by all tested isolates. Isolates $\mathrm{CF}-01$, CF-02 and CF-04 produced intermediate reaction, $\mathrm{CF}-03$ and CF-07 resistant reaction whereas $\mathrm{CF}-05$ and $\mathrm{CF}-06$ produced susceptible reaction.

Statistically all the treatments (Stalk isolates) were non significant on differentials Baragua, Khakai, SES 594, Bo 91, CoC 671, Co 997, Co 62399 and CoS 8436 with respects to pathogenic reactions but these treatments were significant on differentials Co 767, Co 7717, CoJ 64, Co 1148, Co 419, and Co 975.

On the basis of reaction expressed by 7 stalk isolates on 14 differentials and they can be grouped into 4 pathotypes based on their virulence (Table 8). Isolates CF-05 and CF- 06 from CoJ 85 produced susceptible reaction on 10 , and resistant on 4; Isolates CF-03 from CoJ 82 showed susceptible reaction on 8 and resistant on 6; Isolates $\mathrm{CF}-04$ from $\mathrm{CoJ} 83$ produced susceptible reaction on 6 , intermediate on 4 and resistant on 4 ; Isolates CF-01, CF-02 form CoJ 64 and CF-07 from CoJ 88 produced susceptible reaction on 5 ; intermediate reaction on 4 and resistant reaction on 6 .

The Four pathotypes were designated as $\mathrm{CF} \mathrm{Pb}-1$ from $\mathrm{CoJ}$ 85 (Isolates CF-05 and CF-06); CF Pb-2 from CoJ 82 (Isolate CF-03); $\mathrm{CF} \mathrm{Pb}-3$ from $\mathrm{CoJ} 83$ (Isolate CF-04); $\mathrm{CF} \mathrm{Pb-4}$ (Isolates CF-01, CF-02 from CoJ 64 and CF-07 from CoJ $88)$. CF Pb-1 was highly virulent pathotype and produced susceptible reaction on 10 differentials out of 14 followed by $\mathrm{CF} \mathrm{Pb}-2$ pathotype. Pathotype $\mathrm{CF} \mathrm{Pb}-4$ was found the least virulent pathotype which produced susceptible reaction only on 5 differentials namely Khakai, CoC 671, Co 997, CoJ 64 and Co 62399. However, no differences among isolates from a particular variety were observed.

The results of midrib isolates were supported by earlier studied by Butler (1906), Rafay and Singh (1957a), Sandhu et al. (1974), Lewin et al. (1978); Waraitch (1987). Butler (1906) who reported substantial stalk rot after using midrib isolates. Rafay and Singh (1957b) reported midrib isolates caused mild infection. On the other hand, stalk inoculation with midrib isolates showed that most of them are either nonpathogenic or weakly pathogenic reported by Agnihotri and Budhraja (1974). Sandhu et al. (1974) reported midrib midrib isolates were less virulent in comparison with stalk isolate when tested on stalk. The pathogenic capabilities of midrib isolates capable of causing stalk infection reported from Andhra Pradesh by Lewin et al. (1978). Shukla et al. (2001) also cconcluded that midrib isolates were not an imminent danger to the cane cultivation unless these mutate to produce some highly virulent 


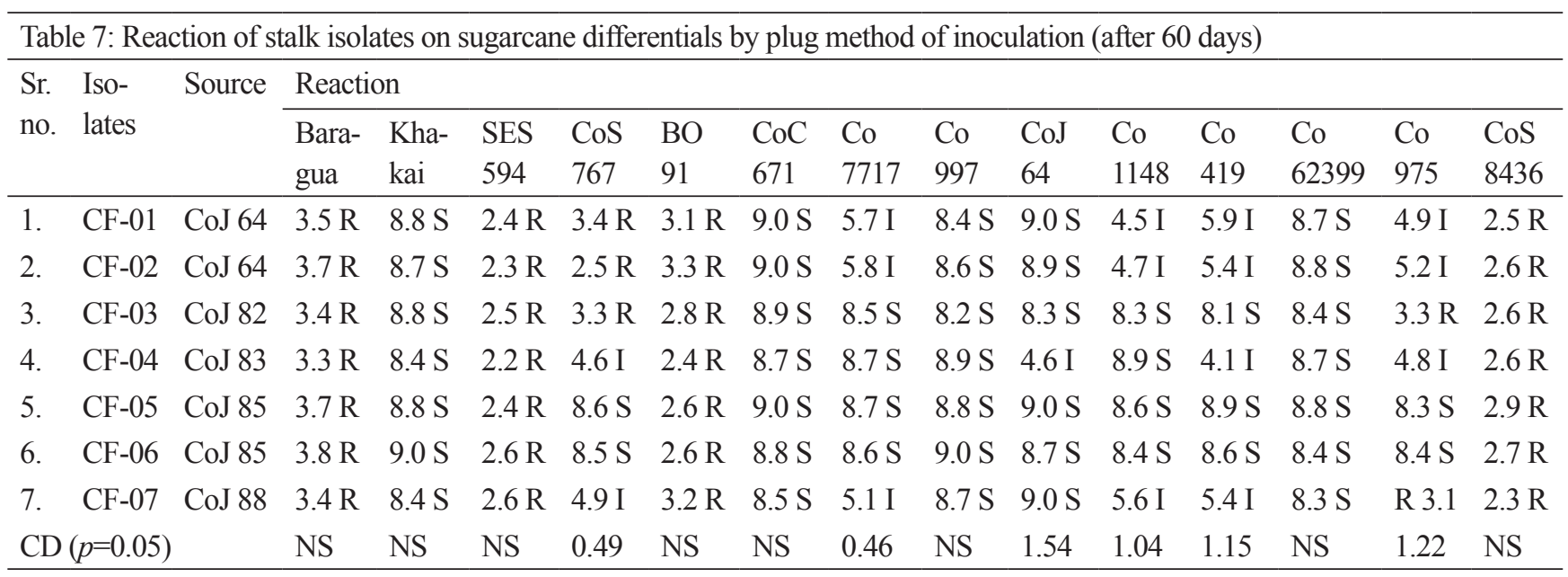

Score-Rating; 0-4.0: Resistant (R); 4.1-6.0: Intermediate (I); >6.1: Susceptible (S)

Table 8: Pathogenic groups of various stalk isolates of Colletotrichum falcatum formed on the basis of Virulence

\begin{tabular}{llllll}
\hline $\begin{array}{l}\text { Group } \\
\text { no. }\end{array}$ & Isolates & \multicolumn{2}{c}{ Reaction } & $\begin{array}{l}\text { Pathogenic } \\
\text { group }\end{array}$ \\
\cline { 3 - 6 } & & \multicolumn{6}{c}{ R } & I & S & \\
\hline Group I & CF-05 and CF- 06 & 4 & - & 10 & CF Pb-1 \\
Group II & CF-03 & 6 & - & 8 & CF Pb-2 \\
Group III & CF-04 & 4 & 4 & 6 & CF Pb-3 \\
Group IV & CF-01, CF-02 and & 5 & 4 & 5 & CF Pb-4 \\
& CF-07 & & & & \\
\hline
\end{tabular}

race which may infect the cane stalks or some possibility of midrib isolates getting adapting to the local host varieties under local conditions to infect cane stalks.Similar results of pathogenic variability in the red rot pathogen were found by Khirbat et al., 1980; Beniwal et al., 1989; Kumar et al., 1994; Anonymous, 1992; Satyavir et al., 1995; Anonymous, 1999; Singh, 2000. Three pathotypes based on differential reaction on three differential varieties CoL 29, Co 62399 and Co 312 were reported by Khirbat et al., 1980. Subsequently studies by Beniwal et al. (1989) also reported the existence of three pathotypes based on differential reaction on varieties Co 7717 and Co 1148 by plug and nodal method of inoculation. The results are also supported by Prakasam et al. (2000) who reported identification of five races of the pathogen based on differential host studies viz., Cf 1148, Cf 7717, Cf 671, Cf 90063 and Cf 92061. Kumar and Virk (2001) reported five pathotypes using 13 host differentials. Nageswararao and Patro (2005) also reported four pathotypes using 12 host differentials and he studied on pathotype reaction of Cf 997 in Andhra Pradesh. The current study confirmed the existence of four pathotypes in all the test isolates of $C$. falcatum using 12 host differentials. Cf 419 and CfBdkh were of the same pathotype (A), whereas Cf 86032 and Cf 87044 fell into another group designated as pathotype D. Isolates Cf 671 and Cf 89 V 74 were of two different pathotypes designated as pathtype $\mathrm{B}$ and pathotype $\mathrm{C}$, respectively. In the present study, pathotype $\mathrm{D}$ (Cf 86032 and $\mathrm{Cf} 87044$ ) resembled that of Cf 997. CfBdkh (pathotype A) and Cf 86032, Cf 87044 (pathotype D), are supposedto be two new reports of $C$. falcatum pathotypes from Orissa.

Mishra and Behera (2009) They were used twelve sugarcane differentials for the study of resistant and susceptibility reactions of different pathotypes of $C$. falcatum isolates and reported seven differentials viz., Baragua, SES-594, CoS 767, Bo 91, Co 7717, Co 1148, and Co 975 showed resistant reactions to $\mathrm{Cf} 419$ and CfBdkh. Differentials viz., Khakai, SES 594, CoS 767, Bo-91, Co 7717, and Co 419 exhibited resistant reactions to $\mathrm{Cf}$ 671, whereas differentials viz., Baragua, Khakai, SES 594, CoS 767, Bo 91, Co 7717, CoJ64, Co 1148, Co 975, and Co 419 exhibited similar resistant reactions for both $\mathrm{Cf} 86032$ and Cf 87044 . Six differentials viz., CoC 671, Co 7717, Co 997, CoJ 64, Co 975, and Co 419 behaved differently, showing susceptible reactions to Cf $89 \mathrm{~V} 74$ and rest of the differentials were resistant. Reaction to SES 594, CoS 767, Bo 91, Co 7717, and Co 419 was resistant to Cf 671 and susceptible to Baragua, CoC 671, Co997, CoJ64, Co1148, and Co975. The different reactions were observed in Baragua, Khakai, Co997, Co1148, Co975, and Co419 and for isolates Cf 419 and Cf 671. This clearly indicated the existence of pathogenic variability among Cf 419 and Cf 671 . Cf 419 and CfBdkh also behaved in a similar manner. But Cf 86032 and Cf87044 showed their virulence only to differentials CoC671 and C0997, whereas others were resistant. The virulence of different $C$. falcatum isolates clearly indicated the presence of four separate pathotypes among the isolates viz., pathotype A-Cf 419 and CfBdkh; pathotype B-Cf 671; pathotype C-Cf 89V74 and pathotypes D-Cf 86032 and Cf 87044. 


\section{Conclusion}

Morphological, cultural and pathogenic variability were exist among seven isolates of $C$. falcatum, causes midrib and stalk of sugarcane. Morphological characters of midrib isolates represent dark type and stalk isolates produced with light and dark type colony colour. Pathogenic variability in midrib and stalk isolates of $C$. falcatum was studied on fourteen host differentials. On the basis of reaction expressed by seven midrib red rot isolates were grouped into five pathotypes based on their virulence. Group I designated as MR Pb- 1 from CoJ 85 was highly virulent and stalk red rot isolates were grouped into four pathotypes based on their virulence. Group I designated as $\mathrm{CF} \mathrm{Pb}-1$ from $\mathrm{CoJ} 85$ was highly virulent. However, no differences among isolates from a particular variety were observed.

\section{References}

Abbott, E.V., 1935. Physiological specialization in Colletotrichum falcatum Went. Proc. Institute of Sugarcane Technology 5, 730-36.

Abbott, E.V., 1938. Red rot of sugarcane. Technical BulletinU.S. Department ofAgriculture 641, 96.

Agnihotri, V.P., 1983. Disease of Sugarcane. Oxford and IBH Publishing Co, New Delhi, 363.

Agnihotri, V.P., 1990. Diseases of sugarcane and sugarbeet. Oxford and IBH Publishing Co. Pvt. Ltd., New Delhi.

Agnihotri, V.P., 1996. Current sugarcane diseases scenario and management strategies. Indian Phytopathology 49, 109-15.

Agnihotri, V.P., Budharaja, T.R., 1974. Pathogenic potentialities of midrib isolates of Colletotrichum falcatum in inciting stalk rot of sugarcane. Sugarcane Pathology Newsletter 11/12, 19-21.

Agnihotri, V.P., Singh, K., 1977. Seed-piece transmissible diseases ofsugarcane and their chemical control. Sugar Newsletter 2, 90-95.

Agnihotri, V.P., Madan V.K., Lal, R., 1989. Changes in carbohydrates and nucleic acids in sugarcane genotypes affected with Colletotrichum falcatum on Sugarcane 4,7 .

Agnihotri, V.P., Madan, V.K., Lal, R., 1992. Proliferation of Colletotrichum falcatumin sugarcane genotypes and changes in sucrose content ofaffected tissues. Indian Sugar 42, 103-05.

Anonymous, 1992. Technical Report-Plant Diseases (199192) Proceedings of the Plant Pathology group. All India Coordinated Research Project on Sugarcane at I.I.S.R. Lucknow.

Anonymous, 1999. Annual Report-Plant Pathology (1998-99). AICRP on Sugarcane, I.I.S.R, Lucknow.
Beniwal, M.S., Satyavir, Virk, K.S., 1989. Pathogenic variability in Colletotrichum falcatum incitant of red rot of sugarcane. Indian Phytopathlogy 42, 95-98.

Butler, E.J., 1906. Fungus diseases of sugarcane in Bengal. Memoirs of Department of Agriculture, India, Botanical Series 1, 2-24.

Chona, B.L., Srivastava, D.N., 1960. Variations in Colletotrichum falcatum, the causal organism of red rot of sugarcane. Indian Phytopathlogy 13, 58-65.

Jothi, R., 1989. Studies on variation in red rot pathogen Colletotrichum falcatum Went on sugarcane. Ph.D. dissertation, Bharathiyar University, Coimbatore.

Khirbat, S.K., Satyavir., Beniwal, M.S., 1980. Physiological and pathological variability in sugarcane red rot pathogen, Colletotrichum falcatumin Haryana. Indian Phytopathlogy 33, 296-99.

Kumar, A., Virk, K.S., 2001. Pathogenic variability in Colletotrichum falcatum in Haryana.Indian Phytopathlogy 54, 505.

Lewin, H.D., Muthusam, S., Sanjeevi, P.S., 1978. Role of midrib isolates of Glomerella tucumanensis in causing red rot of sugarcane. Sugarcane Pathology Newsletter 20, 13-16.

Mishra, M.K., Behera, B., 2009. Pathogenic and molecular variability of Colletotrichum falcatum Went. Isolates from sugarcane with red rot disease symptoms. Journal of Crop Science Biotech 12(1), 31-36.

Nageswararao, G.V., Patro, T.S.S.K., 2005. Pathotypes in Colletotrichum falcatum Went and identification of resistant sugarcane clones. Journal of Mycology and Plant Pathology 35, 305-309.

Pandey, L.N., Sakel, R., 1974. New Pathogenic strain of Glomerella tucumanensis (Speg.) Arx and Muller in Uttar Pradesh. Indian Sugar 24, 707-709.

Prakasam, R., Venkatareddy T.C., 1961. Occurrence of light race of Colletotrichum falcatum Went in Andhra Pradesh. Science and Culture 27, 250-51.

Rafay, S.A., Singh, V.B., 1957a. The role of red rot lesions on midribs. Sugarcane Research and Development Workers, $3^{\text {rd }}$ Conference 335-338.

Rafay, S.A., Singh, V.B., 1957b. A new strain of Glomerella tucumanesis. Current Science 26, 19-20.

Sandhu, S.S., Mehan, V.K., Singh, K., 1974. Role of leaf midrib lesions in epidemiology of red rot causead by Colletotrichum falcatum Went in Punjab. Indian Sugar $18,537-540$.

Sarkar, A., 1960. Comparative study of two races of Colletotrichum falcatum Went. Science and Culture 26, 83- 84.

Sharma, M.N., 1970. Occurrence of new strain of Physalospora 
tucumanesiss peg. in Nizamabad District of Andhra Pradesh. Science and Culture 36, 52-54.

Satyavir, Virk, K.S., Kumar, A., 1995. Resistance of sugarcane genotypes against red rot pathogen. In: ProcNational Seminar on Sugarcane Production, Constraints and Strategies for Research and Management of Red Rot. Part II. Agnihotri, V.P., Sinha, O.K., Singh, R.P. (ed), I.I.S.R., Lucknow, 244-258.

Shukla, R.K., Pandey, A.K., Singh, S.P, Verma, K.P., Singh, R.R., 2001. Studies on comparative pathogenic behavior of stalk and midrib isolates of red rot pathogen. Indian Sugar 50,175-180.

Singh, N., 2000. Identification of pathotypes/races of red rot pathogen. Annual Report for 1999-2000, Sugarcane Breeding Institute, Coimbatore, 64.

Srinivasan, K.V., Bhatt, N.R., 1961. Red rot of sugarcanecriteria for grading resistance. Journal of Indian Botanical Society 11, 566-77.

Srinivasan, K.V., 1969. Physiology of disease resistance in sugarcane with particular reference to red rot. In:
Proceedings, Indian Academy of Science 59(5), 120132.

Viswanathan, R., Malathi, P., Padmanaban, P., 2003. Variation in sugarcane red rot pathogen Colletotrichum falcatum Went. In: Rao, G.P., Manoharachari, C., Bhat, D.J., Rajak, R.C., Lakhanpal, T.N. (Eds.), Frontiers of Fungal Diversity in India, 639-667.

Vishunavat, K., Kolte, S.J., 2005. Essentials of Phytopathological techniques, Kalyani Publishers, Noida.

Waraitch, K.S., 1986. Pathogenic behaviors of isolates of sugarcane red rot fungus. Bharatiya Sugar 11(3), 2436.

Waraitch, K.S., 1987. Comparative pathogenic behaviour of stalk and leaf midrib isolates of red rot pathogen (Colletotrichum falcatum Went). Cooperative Sugar 18(5), 315.

Went, F.A.F.C., 1893. Het Root Snot. Arch. Java Suikerindustries 1, 265-282. 